etablierte Gebührenordnung ab. Wir müssen jetzt signalisieren, dass wir als Zahnärzte diesen Weg nicht mitmachen. Wenn unser Berufsstand angefeindet wird, dann werde ich zum Kampf aufrufen." Mit diesen eindringlichen Worten schloss die standespolitische Podiumsrunde des 48. Winterkongress der Zahnärzte ab.

Am Rande teilte Schrader mit, dass der gesamte Vorstand von der Gastfreundlichkeit des neuen Kongressorts Ischgl sehr angetan sei. Der Vorstand habe deshalb beschlossen, den Winterkongress auch in den nächsten Jahren dort abzuhalten.

Martin Duschek, freier Journalist

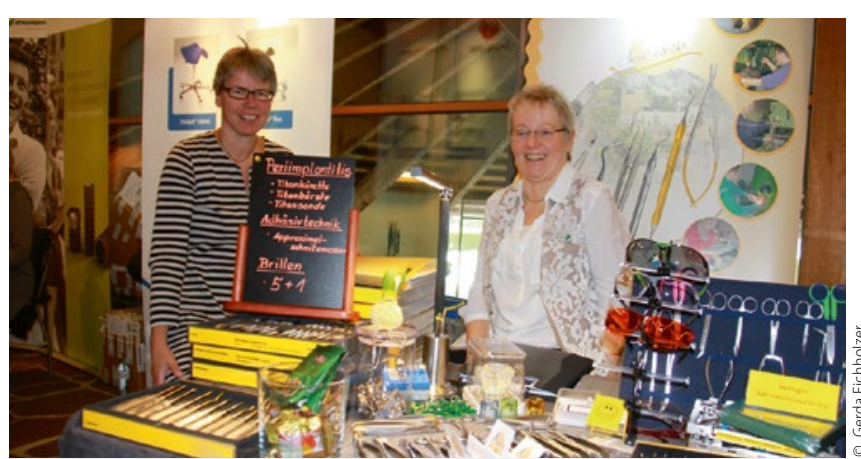

„Das Geschäft läuft gut, aber wir haben noch Luft nach oben!"

„Es ist richtig was los!“

Martina Berkel, Solinger Sabine Ernst, Nitzbon

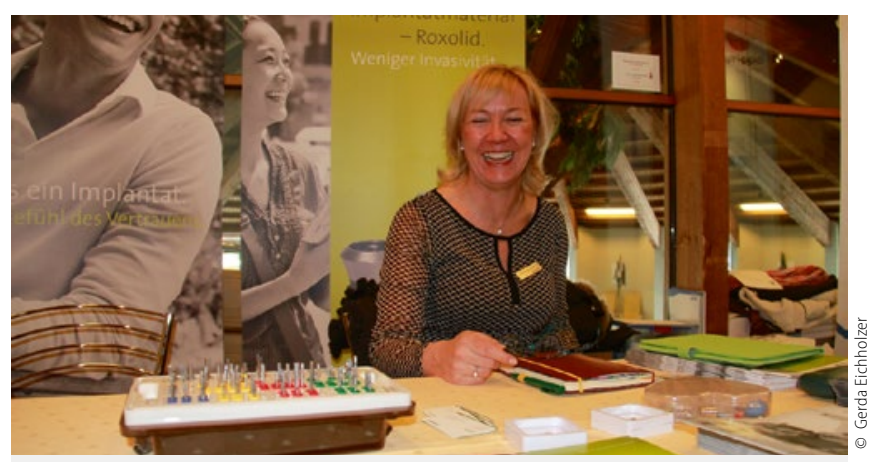

„Interesse der Besucher ist da, und das Catering ist sehr gut.“ Anna Christina Mannola, Straumann

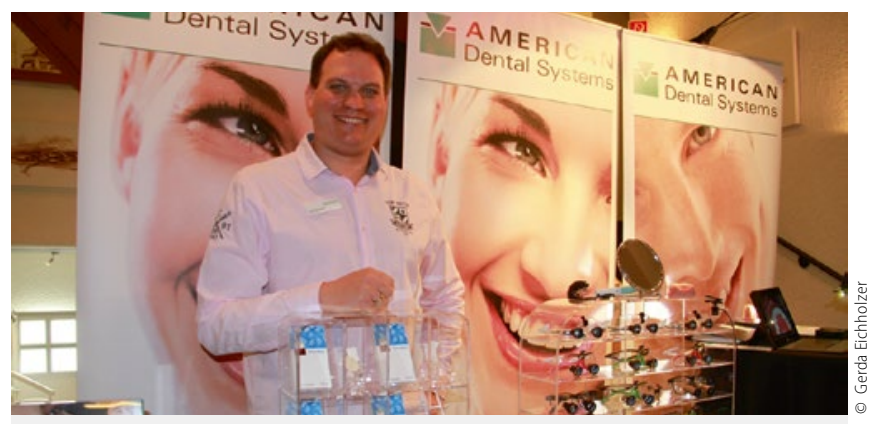

„Ischgl ist Geschmacksache - mir gefällt's.“ Rene Eisenweger, American Dental Systems

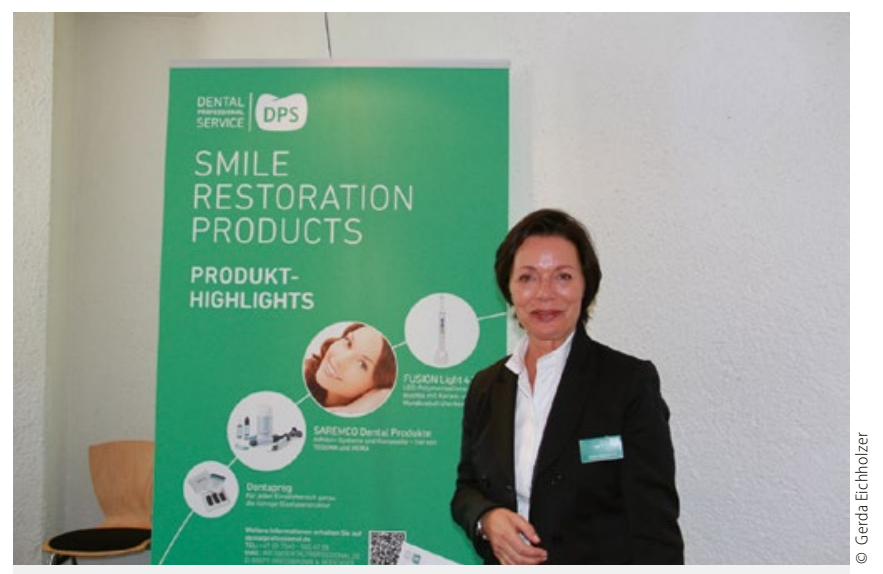

„Hier herrscht viel mehr Remmidemmi!“ Petra Oberscheid, DPS

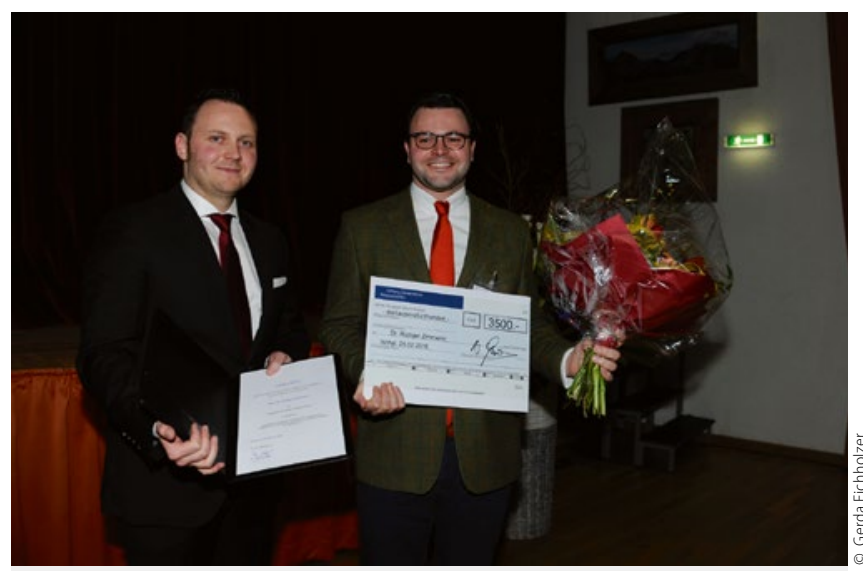

Förderpreis der Stiftung Zahnärztliche Wissenschaften überreicht

\section{Würdiger Preisträger aus Hannover}

Auch auf dem 48. Winterkongress der Zahnärzte konnte ein überaus würdiger Preisträger mit dem Förderpreis der Stiftung Zahnärztliche Wissenschaften ausgezeichnet werden.

FVDZ-Vorstandsmitglied Dr. Thomas Wolf überreichte den diesjährigen Förderpreis und erinnerte an die auf den Tag 115 Jahre zurückliegende Geburt des zweifachen Nobelpreisträgers Linus Pauling: „Ich suche gezielt nach Arbeiten, deren Resultate mir Kopfzerbrechen machen.“ Dies sei auch die Haltung, mit der sich Dr. Rüdiger Zimmerer von der Medizinischen Hochschule Hannover den mit 3.500,00 Euro dotierten Förderpreis verdiene.

Zimmerer wurde für seine Arbeit zum Thema „Erstellung eines biomechanischen Profils vaskularisierter, präfabrizierter, bioartifizieller Konstrukte unter Berücksichtigung der Mikrostruktur" ausgezeichnet. In der Pilotstudie erstellte der Wissenschaftler erstmals einen Arbeitsablauf, mit dem die biomechanischen Eigenschaften eines neuartigen Knochenersatzmaterials beurteilt werden konnten, um dessen Einsatz im klinischen Alltag zu ermöglichen. Zimmerer ist in der Weiterbildung zum Mund-, Kieferund Gesichtschirurg an der Klinik und Poliklinik für Mund-, Kiefer- und Gesichtschirurgie der Medizinischen Hochschule Hannover tätig. In einem rund zehnminütigen Referat gelang es Zimmerer, seinen Forschungsgegenstand anschaulich und eindrucksvoll dem Fachpublikum vorzustellen.

Die Preise der Stiftung Zahnärztliche Wissenschaften werden jedes Jahr vom FVDZ ausgelobt. Für den Förderpreis 2017 können wissenschaftliche Arbeiten bis zum 31. Oktober 2016 bei der FVDZ-Bundesgeschäftsstelle eingereicht werden. Weitere Informationen finden Sie unter dem Stichwort „Förderpreis" auf der Verbandswebsite www.fvdz.de.

mad 